\title{
Erratum zu: Einführung von Public Cloud Services - Herausforderungen und Lösungsansätze aus der Praxis
}

\author{
Stefan Brassel • Andreas Gadatsch (iD
}

Angenommen: 12. Mai 2021 / Online publiziert: 25. Juni 2021

(C) Der/die Autor(en) 2021

\section{Erratum zu:}

\section{HMD 2020}

https://doi.org/10.1365/s40702-020-00652-5

Der Artikel Einführung von Public Cloud Services - Herausforderungen und Lösungsansätze aus der Praxis von Stefan Brassel und Andreas Gadatsch wurde ursprünglich Online First ohne „Open Access“ auf der Internetplattform des Verlags publiziert. Nach der Veröffentlichung in Bd. 57 Heft 5 pp. 949-960 hatten sich die Autoren für eine „Open Access“-Veröffentlichung entschieden. Das Urheberrecht des Artikels wurde deshalb in (C) Die Autoren 2020 geändert.

Funding Open access funding enabled and organized by Projekt DEAL.

Open Access Dieser Artikel wird unter der Creative Commons Namensnennung 4.0 International Lizenz veröffentlicht, welche die Nutzung, Vervielfältigung, Bearbeitung, Verbreitung und Wiedergabe in jeglichem Medium und Format erlaubt, sofern Sie den/die ursprünglichen Autor(en) und die Quelle ordnungsgemäß nennen, einen Link zur Creative Commons Lizenz beifügen und angeben, ob Änderungen vorgenommen wurden.

Die in diesem Artikel enthaltenen Bilder und sonstiges Drittmaterial unterliegen ebenfalls der genannten Creative Commons Lizenz, sofern sich aus der Abbildungslegende nichts anderes ergibt. Sofern das betref-

Die Online-Version des Originalartikels ist unter https://doi.org/10.1365/s40702-020-00652-5 zu finden.

\author{
Stefan Brassel \\ „License \& Cloud Technology Consulting“, Bechtle AG, Aachen, Deutschland \\ E-Mail: Stefan.brassel@bechtle.com \\ Andreas Gadatsch $(\square)$ \\ Hochschule Bonn-Rhein-Sieg, Sankt Augustin, Deutschland \\ E-Mail: Andreas.Gadatsch@h-brs.de
}


fende Material nicht unter der genannten Creative Commons Lizenz steht und die betreffende Handlung nicht nach gesetzlichen Vorschriften erlaubt ist, ist für die oben aufgeführten Weiterverwendungen des Materials die Einwilligung des jeweiligen Rechteinhabers einzuholen.

Weitere Details zur Lizenz entnehmen Sie bitte der Lizenzinformation auf http://creativecommons.org/ licenses/by/4.0/deed.de. 